\title{
Becoming Competent in Palliative Care as Perceived by Nurses Attending a Master Programme. A Qualitative Study
}

\author{
*M. Benedetta Gambacorti-Passerini ${ }^{1}$, Anne Destrebecq ${ }^{2}$, Stefano Terzoni ${ }^{3}$, Lucia Zannini ${ }^{2}$
}

${ }^{1}$ Research fellow, University of Milan, Department of Biomedical Sciences for Health, Italy

${ }^{2}$ Associate Professor, University of Milan, Department of Biomedical Sciences for Health, Italy

${ }^{3}$ Tutor nurse and lecturer in Nursing, University of Milan, San Paolo teaching Hospital (Milan), Italy

Received: March 07, 2017; Accepted:March 29, 2017; Published: May 02 , 2017

*Corresponding author: M. BenedettaGambacorti-Passerini, Research fellow, University of Milan, Department of Biomedical Sciences for Health, Italy, Tel: +39-02-50315101; E-mail: mbenedetta.gambacorti@gmail.com

\begin{abstract}
This study analysed the perceived process of developing competence in a group of nurses attending a University Master programme in Palliative Care (PC). To evaluate and monitor PC competences, validated questionnaires are available in the literature. Nevertheless, nursing competence in PC is not always evident and measurable. Qualitative instruments as interviews, focus groups could be useful to explore that aspect of nurses expertise and to better evaluate the development of competence in PC during and after training experiences.
\end{abstract}

Since we focused on a process, we opted to follow the Grounded Theory method. Data were collected through three focus groups, carried out at the beginning, in the middle and at the end of the training. All the nurses participating in the programme were involved.

The development of nurses' competence in PC turned out to be characterised by: 1) transforming clients' representation from a fixed and uniformed image of the patient to a multi-faceted idea of him/her; 2) transforming the idea of the family from an obstacle to a system integrated with patients; 3 ) proceeding from an idealized representation of the team to its perception as a real working group; 4) experiencing the accompanying to death as a feasible team work and no more as a solitary endeavour; 5) shifting from a focus just on relational needs to competence in a global patient's management.

Nurses who apply for post-graduate PC training appear to have high predisposition towards considering communicative/ relational competences as crucial in that field. Nevertheless, they should be oriented to critically reflect on these core competences to transform their often idealised, and therefore self-protective, image of patients.

Keywords: Grounded Theory; Nurses' competence; Palliative care; Post-graduate palliative care training; Qualitative study.

\section{Introduction}

In Italy, oncological diseases cause more than 100,000 deaths every year: approximately $90 \%$ of them need Palliative Care (PC) (ISTAT, 2012). Patients suffering from non-oncologic, chronic diseases may require PC as well (ISTAT, 2012). Italian data, like those from European and Western countries, highlight the emerging need for palliation and trained professionals in this area [1].

PC is an emerging healthcare branch, strongly expanding also in Italy. The Italian Law 38/2010 enacts the effort to guarantee the best quality of life to all patients affected by terminal diseases [2]. Thus, educating professionals in PC is a crucial aspect. The Italian Society of PC by referring to European guidelines and directives, has pointed out the core competences that must be achieved by professionals working in PC [3-5].

The Italian Society of Palliative Care ("SICP") has identified a mix of specialised, organizational and tacit competences as the core curriculum in PC [6]. Professional competence is based on various factors, such as actions, knowledge, values, and beliefs, largely determined and created by context and human relationships. Empathic listening skills, a keen perception, and understanding based on various forms of professional knowledge are considered pivotal elements of communication skills in PC [7].

Specialised and technical skills are crucial for curing symptoms and physical pain, but they must be integrated with the ability to take care of the person, his/her family and his/her spiritual [8] and psychological needs in order to offer a holistic care [9-11]. Interdisciplinary collaboration is then advised to acquire the ability to address patients and families different needs [12].

Nurses are fundamental in PC, as they care for patients and their families every day. In order to provide competent and effective PC, nurses need specific training $[13,14]$. Nursing 
education in PC, which addresses pain and symptom management together with psychosocial and spiritual needs, can significantly reduce suffering and provide comfort and dignity to dying patients and their families [15-18].

In Italy, post-bachelor education in PC for nurses is mostly based on a 1-year programme [60 European Credit Transfer and Accumulation System (ECTS)] during which nurses are taught patient assessment, symptom management, communication skills, and spiritual care [19].

According to EAPC [4] and SICP [3], nurses' training must address five fundamental competences: ethical, clinical, communicative-relational, psychosocial and of working in a multi-professional group. These competences are strongly based on the Italian validation of the nursing core curriculum in PC defined by the Project Tuning Educational Structures in Europe [20]. The challenge, in PC training, is not only to accompany nurses to develop those competences, but also to monitor them during the training and later, in their professional practice.

To evaluate and monitor PC competences, validated questionnaires are available in the literature. An example is the Nurses' core competences in palliative care developed by SICP [21]. Several studies use pre-post test design to assess the improvement of nurses' competence as a result of PC training [22-24]. Nevertheless, nursing competence in PC is not always evident and measurable. Some examples are the area of ethical, psychosocial competence, or the capacity of recognising and thinking about crucial questions in PC, like those arising in the dying process, or the challenges posed by working in a multiprofessional team [25-29]. Perceptiveness has been considered as a «vital ability in order to achieve the expert level of nursing» in PC [30]. The authors suggest that this perspective should be taken into consideration when developing a curriculum in PC and, we add, when evaluating the development of nurses' competence in PC.

There is an increasing demand for strategies capable to gather the implicit dimensions of nursing competence in PC $[31,32,28]$. Qualitative instruments as interviews, focus groups (FGs), and autobiographical writings could be useful to explore that aspect of nurses' expertise and to better evaluate the development of competence in PC during and after training experiences [33-35].

This qualitative study is aimed at analysing the development of competence in a group of nurses attending an Italian Master programme in PC (providing for 60 credits ECTS, included clinical learning), considering how nurses perceived their professional growth during the training (Table 1). Analysing the development of competence, from the nurses' perspective, has been considered useful not only for the administrators of the Italian postgraduate programme, but also for those involved in planning, carrying on and evaluating postgraduate nursing curricula in PC.

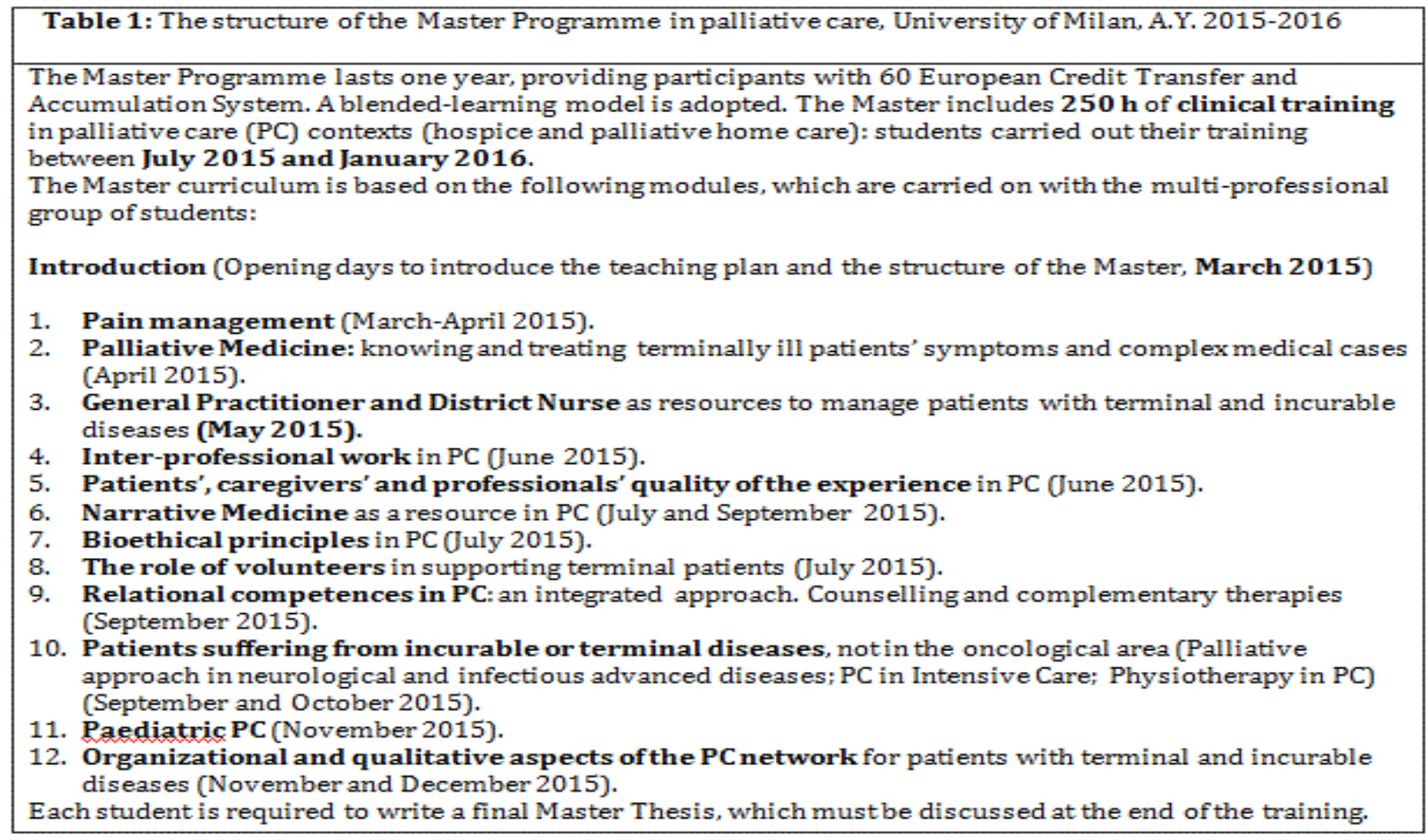




\section{Methods \\ Design}

Framed in a qualitative approach to research [36], this study was based on the Grounded Theory (GT) method [37,38]. As Richards and Morse stated [39], research questions of a GT study "explore process, and its outcomes are midrange theories specific to a particular process and a particular situation" [39].

\section{Participants}

All the 19 nurses (17 females and 2 males) enrolled in the post-bachelor programme 2015-2016 participated in this study. The programme was multi-professional and also involved 10 physicians and 1 Social Worker (SW). We decided to include the latter in the nurses' group because her professional practice was based on caring. Therefore, this study involved 20 participants (19 nurses and 1 SW).
Research participants came from different Italian regions and had different ages and levels of professional experience. They were from 23 to 52 years old [mean: 34.7; Standard Deviation (SD): 9.78], and had between 0 and 20 years of nursing practice (mean: 6.10; SD: 6.77). Referring to PC, their professional experience ranged from 0 to 19 years (mean: 2.10; SD: 3.3). We considered "expert" in the PC area those professionals who had been working there for at least two years [40].

The 19 nurses (numbered N1-N19) had a Bachelor of Sciences in Nursing and the SW had a Master's Degree in Social Sciences.

\section{Data collection}

According to the GT, nurses' development of competence was studied collecting data from three FGs, carried out in different moments of the training: at the beginning (April 2015); after the clinical training (October 2015); and at the end of the activities (December 2015). Participants were divided into two groups, and researchers met every group three times to collect data (Table 2).

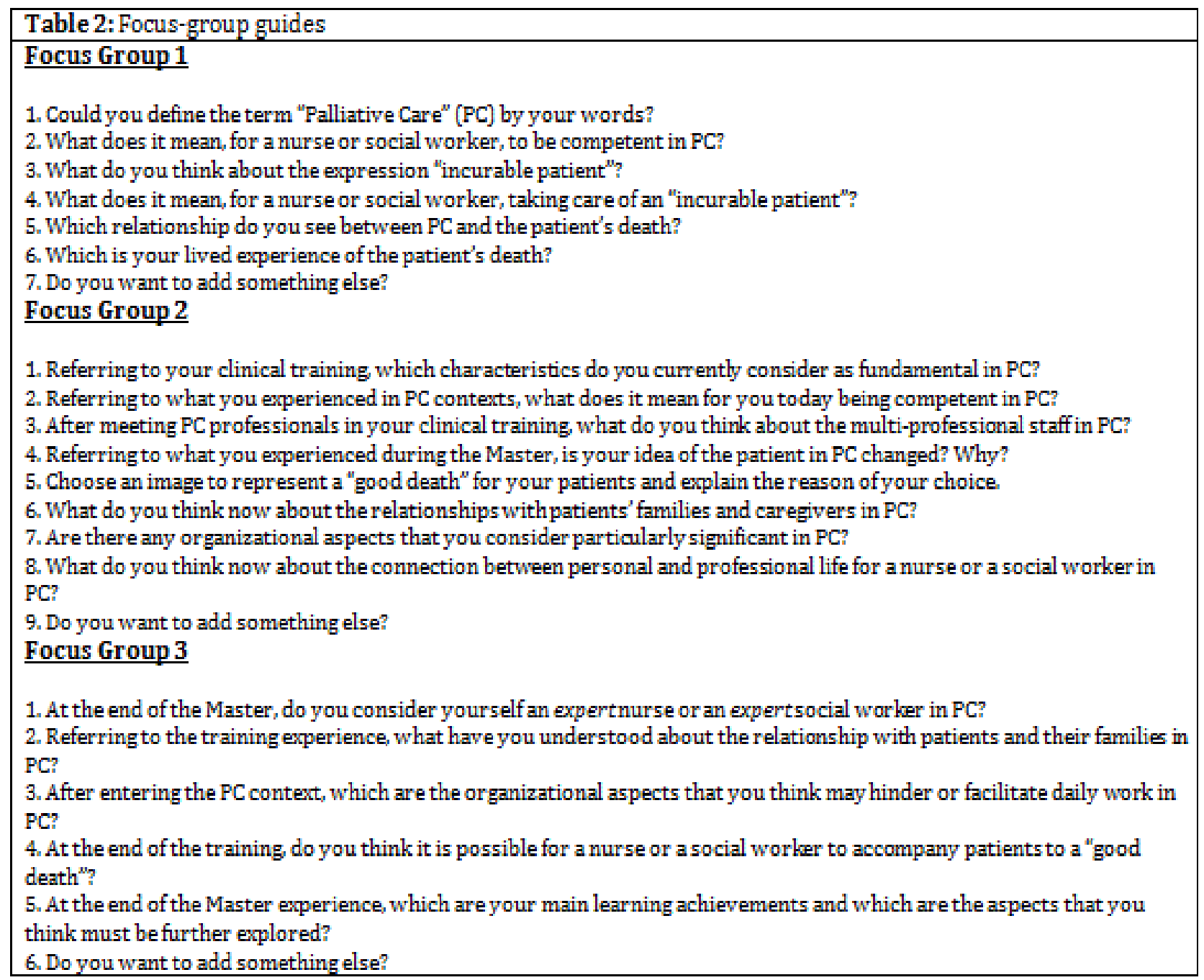


In total, six FGs were carried out, each lasting between 1.5 and $2 \mathrm{~h}$. The same two researchers conducted all FGs in a quiet space, close to the Master lecture hall. One of them had no relationship with the participants, while the other was involved in the last part of the Master programme as a lecturer (10 h). Every FG was audiotaped and, then, verbatim transcribed.

\section{Ethical aspects}

Approval for the study was obtained from the Ethical Board of the University of Milan. In addition, every participant was asked to sign a written informed consent for every FG, agreeing to the audio-taping and to the use of the data for research and publication. Confidentiality was ensured to all participants.

\section{Analysis}

Following the GT method, two researchers independently analysed data before sharing and discussing every passage of the analytic process [38].

The transcripts were examined line by line. Then, a label referring to a group of words was applied (initial coding). By using gerunds, we focused on what the participants were doing or the (mental) action that was taking place within the segment of data. Our codes tried to identify "participants' tacit assumptions" and illuminate "their implicit actions and meanings" [41].

Afterwards, initial codes were sorted and researchers discussed which ones were the most frequent and significant. By doing so, for each FG transcription, we created groups of initial codes that pertained to a particular focused code. In order to gain a deeper understanding of the focused codes, we compared them in each FG held during the training. In the meanwhile, we wrote analytic memos about what we learnt in this iterative process. Finally, focused codes were grouped together to form a category. Therefore, categories related to the first round of FGs were compared with categories derived from the second and the third round of FGs. This passage too was independently done by researchers at first and subsequently discussed together in order to reach a shared formulation of categories.

An external audit for identifying categories was asked to a nurse researcher expert in PC, which led to the revision of two categories.

Finally, by comparing categories from the three rounds of FGs, we outlined the process of development of nurses' competence in PC, relying on the experience of nurses who attended the Master programme in PC.

\section{Results}

Five macro-categories emerged from the analysis of the six FGs. According to the GT method, the central phenomenon experienced by the participants was the change of defining as competent a nurse providing PC. In this sense, the first category 1), named "Becoming a competent nurse in PC: from a focus just on relational needs to a global patient's management", could be represented as the core category of the analytic process. The other categories showed particular aspects of the change of defining a nurse as competent: 2) "Transforming patients' representation: from a fixed and uniformed image to a multi-faceted and unique patient"; 3) "Developing families' representation: from an obstacle to a system integrated with patients"; 4) "Proceeding from an idealized representation of the PC team to the feeling of being part of a real working group"; 5) Accompanying to death: from a burdensome and solitary endeavour to a feasible goal reached through teamwork (Figure 1).

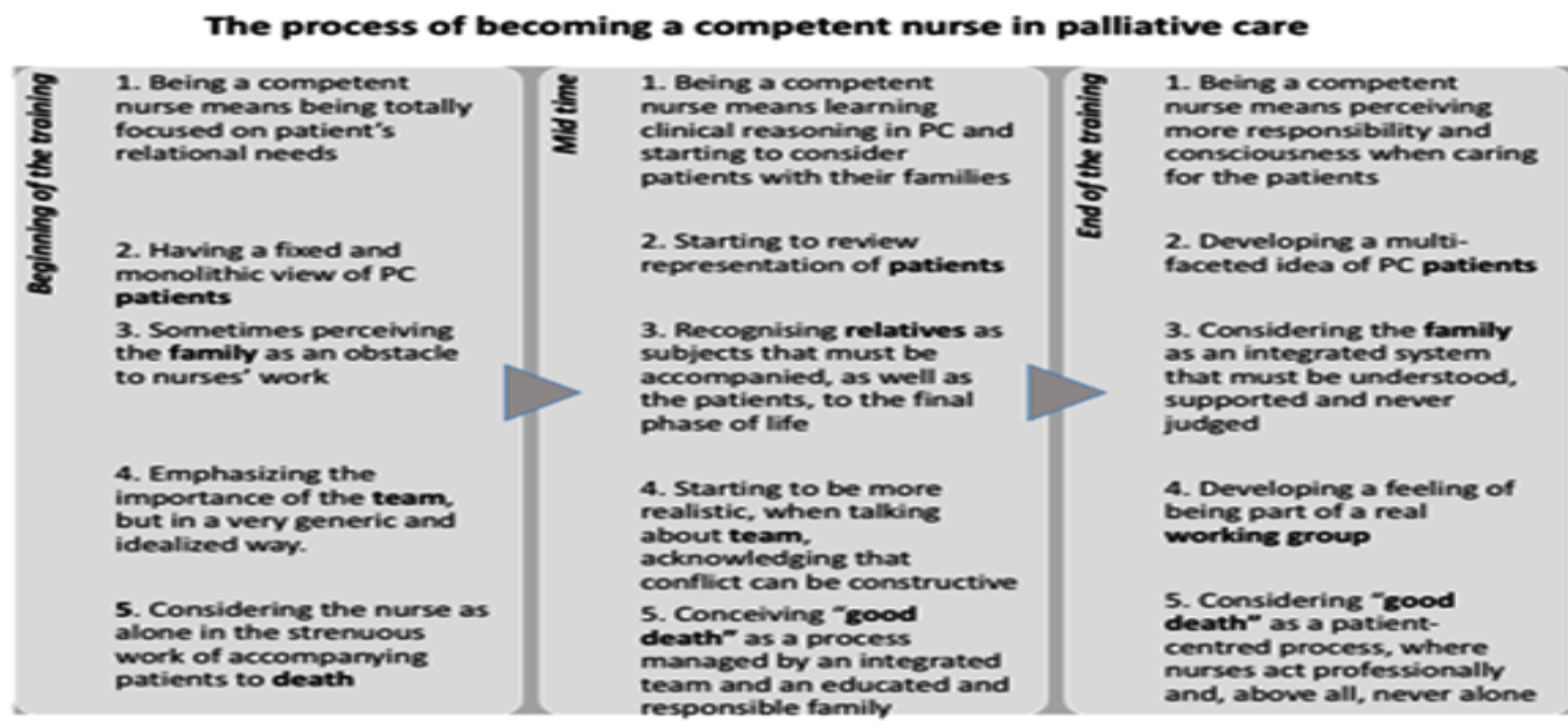

Figure 1: The process of becoming a competent nurse in palliative care 


\section{Macro-category1: Becoming a competent nurse in PC: from a focus just on relational needs to a global patient's management}

At the beginning, participants represented competence in PC referring mostly to single abilities, particularly focused on patients' relational needs: Sensitivity is the particular element of nursing PC competence (N10). Competence in PC is being able to listen to patients and families (N3).

Initially, nurses were totally focused on patients and their needs, while their role and caring work remained on the background. It seemed that nurses were completely absorbed in offering relational support to the patients, while their competences (i.e., symptoms management) were underestimated or taken for granted (this pertained especially young nurses, who had just completed their Bachelor).

In the middle of the course, nurses began considering the fact of having experience and being conscious as crucial for becoming competent in PC: A competent nurse in PC must learn to reason (...) and to consider the global context of patients and families (N4). In addition, the importance of continuous training was affirmed in order to maintain and develop competence, especially with reference to the ability of working in a group: In my opinion, a competent nurse in PC is the one who is adequately and continuously trained and who is able to work in a group (N14).

In the last part of the course, nurses became more selfconfident about their role and responsibilities in PC: Now I perceive that $P C$ nursing competence is constituted of more responsibility and consciousness of caring, (N10). Nurses would focus on a patient-centred approach, which was then managed with more expertise: After the Master I perceive myself as more expert, not only in technical aspects, but also in the human ones (N16).

In the last FG, nurses declared they felt more confident in decision making and clinical reasoning management, showing a conscious perception of their increased competence. They perceived themselves as more skilful in managing all aspects of PC and patients' needs. At the end of the Master, they expressed a new idea of competence that was considered in its complexity. Particularly, nurses reported a strong idea of being more conscious of a complex and multi-faceted competence, showing their new ability of reflecting on PC competence, thus exhibiting metacompetence.

To conclude, nurses' PC competence changed from a focus just on single abilities and on patients' relational needs to a more complex and aware competence focused on the ability of a global patient's management. Interestingly, no substantial difference was found in this category between expert and novice nurses.

Macro-category 2: Transforming patients' representation: from a fixed and uniformed image to a multifaceted and unique patient

At the beginning of the training, a static and uniformed view of incurable patients emerged from the participants' words (i.e. the patient is represented as old and almost about to die). Participants expressed the idea that it is always possible to care for those patients, even if terminal: Their pathology is incurable, we can't cure it, but it's possible to take care of them, it is possible to take care of every patient (N11).

Initially, nurses perceived their competence in PC as mainly based on communication/sympathetic closeness: In PC there are pharmacological aspects, surely, but the most important thing for us is to live with the patient his or her last days, helping him/her give meaning to the disease and live these days at the best...I think what mostly matters in our work with patients is the relationship (N12). This relationship is represented as managed by the nurse and therefore mainly focused on the professional, being the patient depicted as the subject receiving care.

In the middle term FG, patients' representation started to be revised, with frequent referring to the experience of clinical training within the Master programme, and new elements were reported: Maybe my point of view was unaware...or maybe I knew that also young patients could be in PC, but I was used to see old people...I feel really a novice (N19).

Practical training with patients gave nurses the opportunity to reflect on patients' representation, both for novice and expert nurses. During the last FG, indeed, the ability to catch patients' uniqueness emerged, as well as the attitude to consider them as the core and the guide of the caring process: Every patient has different pace, different ways of acting; maybe they don't want to achieve what we wish... Now I believe that we shouldn't decide alone what to do, thinking that we will resolve or change... Patients are all different and we must adapt ourselves to their needs and uniqueness (N12).

Overall, the participants' developing process observed could be summarised as follows: from a fixed and uniformed view of PC patients to a more multi-faceted representation of them, in which the ability to catch patients' uniqueness and to consider them as the guide of the caring process is central.

\section{Macro-category 3: Developing families' representa- tion: from an obstacle to a system integrated with pa- tients}

The third macro-category shows a development of the idea of patients' families during the Master. At the beginning, families were represented as part of the patients' existential system, but they were often perceived as an obstacle to the nurses' work: Recently, I had to manage a very hard relationship with a family [...]. It has been quite a tragic experience [...]. I would have wanted to scream my judgement: I never did it, but I felt this inside [...]. I totally didn't agree with their behaviours (N14).

In the middle FG, this representation started to change, mainly due to the experience lived by the nurses during the clinical training, and families started to be seen as subjects that must be accompanied, like the patients, to the final phase of life: Someone [during the clinical training] helped me to understand [...] that the peculiarity of PC is to accompany families, not only patients (N1).

At the end of the training, the final representation of families seemed to be further changed both in novice and expert nurses. Families were not perceived as an obstacle, but rather as an integrated system that must be understood, accepted and never judged: We never have to stop looking for a deeper understanding of families. We have to think about reasons that sustain 
certain disagreeable behaviours: we have to go deeper [in our analysis] in order to offer adequate care to families and patients (N4). Consistently with the process of changing the representation of patients, nurses seemed to develop a richer image of families, which should be considered and understood in their originality and uniqueness, without living diversity as an obstacle.

\section{Macro-category 4: Proceeding from an idealised rep- resentation of the $\mathrm{PC}$ team to the feeling of being part of a real working group}

When monitoring nurses' development of competences, particular attention was devoted to their idea of multi-professional work. At the beginning, participants emphasized the importance of the staff, but in a very generic and idealized way, as if the representation of the multi-professional work was only theory-driven: Working with a good staff is very important, and every conflict must be resolved (N2). The Master experience offered the opportunity to meet real working groups in PC contexts: during the middle FG, in fact, participants' words about team started to be more realistic, referring to the contexts they experienced during the clinical training. This transition from an idealized to a more realistic approach is especially evident in "novice" nurses, who had very little experience in PC: Maybe before I had a very idealized representation of PC team...I was used to talk about it using a lot of beautiful words, but I had never seen before a real good team...during the clinical training I kept in touch with it, there really was the perception of being part of a team (N12). This trend was confirmed at the end of the Master. In the last FG, participants talked a lot about the team, remarking both strengths and difficulties of the multi-professional work: I'm glad when daily discussions in staff are carried on, this is the only way to grow, sharing problems... People can approach problems in different ways, but in a real team you can discuss them, even if it is hard to be done (N17). Particularly, they noted that the Master experience was really important to develop their representation of a PC team: In my opinion, the Master training has been very useful to learn how to work in a staff, understanding how to discuss in a team (N16).

In summary, thanks to the Master experience, nurses proceeded from an ideal representation of the PC team to the feeling of being part of a real working group.

\section{Macro-category 5: Accompanying to death: from a burdensome and solitary endeavor to a feasible goal reached through team work}

Accepting that patients' diseases could not be healed and that they are going to die is considered one of the most difficult aspects of PC. An important part of nurses' work in PC consists in the process of accompanying patients and families to their relatives' death, with professional competence.

As we reported before, the idea of "good death" is hard to be defined and it is highly influenced by subjective and cultural factors. In this sense, this category appears to bevery complex, highlighting a multifaceted process. In all the FGs, participants' words about "good death" referred to the end of the patients' suffering. Death was considered "good" if patients and their families were adequately prepared to it.
Nevertheless, initially nurses talked about general aspects of accompanying patients towards death, not really related to the process of caring and to what they could do professionally: It is very important to help patients, to help them in reconsidering their life, giving meaning to it (N12). This ideal and general representation of accompanying to a "good death" (particularly relevant in "novice" nurses) was conceived, at the beginning of the course, as something that nurses should carry on alone, and therefore as a very demanding work. Initially, even expert nurses, although in a less idealized manner, conceived accompanying the patient to death as a lonely work, in which patients are not leading the process: I have to learn to let the patient guiding the process (N19). At first, nurses seemed to think of themselves as the only professionals involved in this task, alone and quite multitasking.

In the middle of the course, other aspects were introduced by participants, when discussing about a "good death". For instance, the role of the team started to be mentioned: Now, for me, for a "good death" you need warmth, protection, tenderness... so I imagine a good team and an educated and responsible family [accompanying the patient] (SW).

Colleagues and patients' care-givers started to be seen as a crucial support for the difficult work of accompanying to death: post-bachelor education seemed to have developed the idea that accompanying to death should be lived in alliance with other people, without hiding difficulties. The idea of being the only professional involved in accompanying patients to death became fainter and fainter as the Master activities went on. In the middle phase, the process of accompanying to death was likely to be more feasible for participants. In the last FG, a multi-faceted representation of "good death" emerged. It started to be seen in a less ideal and general way, mostly by "novice" nurses, and patients started to be represented as "the centre" of the caring process: Now I think that patient is the fundamental variable in the accompanying process (N12). Nurses emphasized the importance of acting professionally and, above all, never alone: Nurses can offer a great contribution, but they always need other professionals' support, we can't do everything alone (N7).

In the participants' words, the Master experience has improved the capacity of accompanying to die (Master gave me many instruments for the accompanying process. N12), even if participants still highlighted the complexity of the dying process, underlying the necessity of a continuous training on these topics: It's important for me that institutions continuously train PC professionals, really continuously, accompanying them in their daily work [...], because accompanying another person and his/her family to death is an enormous challenge (N19).

\section{Discussion}

Studies have pointed out that nurses often base their professional practice and idea of competence on particular values: as Taylor et al. noted, nurses are commonly perceived as being very committed to the patients they care for [42]. These ideas are particularly stressed in $\mathrm{PC}$, where nurses have to struggle to face patients' end of life and all the existential, ethical passages that this implies, including families' needs [42]. The core concept 
of the PC philosophy, as Dobrina et al. reported, seems to be a patient-centred approach focused on relationship and sensitiveness [13]. Our participants revealed to have deeply internalized this core concept: since the beginning of the Master, they continuously stressed the importance of being sensitive and communicative with patients. In this sense, our study highlights that the applicants to the PC Master already had a predisposition to core aspects of PC and required competences, like setting up a positive relationship with patients and families, and effectively communicating with them. Participants reported these aspects were unique and privileged characteristics of $\mathrm{PC}$, although sometimes idealized, which was particularly evident in novice nurses.

Consistent with our findings, it seems that the first phase of nurses' training in PC should not be focused on emphasizing the aspects related to relational competences. In fact, nurses appear to already have a predisposition towards considering those competences as crucial in PC. Quite the opposite, at the very beginning of PC training, nurses should be oriented to critically reflect on relational aspects of $\mathrm{PC}$, in order to transform their often fixed and idealized image of the patients into a multi-faceted and complex representation of them [43]. Idealization is commonly considered as a defence mechanism and nurses should reflect on their image of the patient,, asking themselves why it is so often idealized. Particularly, our study could offer suggestions for planning PC training: focusing on patients' representation, it should be useful to let PC nurses note that idealizing relational and communicative aspects could be a defence mechanism related to the effort of caring for incurable patients.

Accordingly, nurses should be encouraged to reflect on the image of the patients' family: in our study, at the beginning of the training, relatives were often seen as hindering the nursepatient relationship. However, in the end participants were able to recognize that each family has its own story and that (negative) behaviours should be understood in view of that story, and never judged.

Referring to the representation of the patients' families, cultural aspects must be taken into account: in Latin cultures, like the Italian one, families tend to be both protective and invasive with regard to the patients' wishes. In this sense, our participants initially reported the idea of family as an obstacle, showing a possible connection between our findings and some characteristics of families in Latin cultures [44]. However, the representation of families as obstacles can be considered as "immature". In this sense, our study highlights the importance of working on families' representation, while planning training for PC nurses. Professionals should be helped to understand the story of every family, giving meaning to their behaviours (the positive but also the negative ones) referring to that particular and unique story.

Idealization resulted to be a process that involved not only the patient, but also the PC team. Nurses, at the beginning of the educational programme, were likely to represent the team as a monolithic, powerful solution to all the difficulties that may arise in PC. This representation can be interpreted as the nurses' need to find protection and guidance in the PC team, because they felt alone in facing their hard work. Yet, in the last part of the training, particularly after clinical practice, nurses were able to see the difficulties of the multi-professional work, since the healthcare professionals "can approach problems in different ways". Participants highlighted the importance of discussion and even conflict in the PC team, revealing that being part of a group does not mean delegating decisions to the "protective" team, but taking responsibilities and bringing one's own contribution. To this aim, the so-called "soft skills" are crucial [45].

Communication skills and ethical competences are seemingly the most complex aspects of working in PC. Arnaert \& Wainwright and Selman et al. remarked this complexity, highlighting the need for a continuous professional training focused on those aspects $[32,46]$. Indeed, many participants expressed, at the end of the Master programme, the need for further training focused on those often idealized but complex competences, underlining the idea that education on communication skills is never enough. When planning PC professional training, the importance of dealing with relational aspects must be emphasized, and they must be deeply analyzed in order to break down any idealization and naivety in managing the relationship with terminal patients. At the same time, it should be considered that relational and ethical competences are fundamental and particularly challenging in PC. Frequently, the professionals' feeling is that training in those aspects is crucial and never enough to reach a sense of being competent $[30,7]$.

Our research highlights how participants initially do not regard clinical or pharmacological skills as core aspects of PC competence. The initial idealization of relational and communicative skills in PC seems to dim the importance of a multifaceted competence in order to offer a global care to patients. As Strandberg et al. noted, holistic nurses' practice requires both the managing of social, emotional and spiritual needs, and the clinical and pharmacological expertise, in order to take care of physical pain and symptoms [11]. Our study reveals that the clinical and pharmacological aspects of PC start to be taken into account after a reflective process that challenge participants to deeply reconsider the idea of PC competence. Technical and clinical nursing abilities are fundamental for PC competence: as Heals and Ferrell et al. noted, these aspects must be presented and well addressed in professional training because they are part of a complex and multi-faceted vision of PC competence [19,47].

According to Taylor et al., our findings highlight the importance of transforming future PC nurses into reflective practitioners, skilled in continuously evaluate their competence and professional practice, with the final aim of examining their activities and improving nursing care $[48,7]$.

Particularly, monitoring of the representations of competences can be an interesting strategy to transform PC nurses into reflective practitioners: discussions during the FGs, in fact, were fruitful opportunities for nurses to think about their idea of PC competences, comparing themselves to each other and reflecting on their developing competence.

Reflective aptitude is considered as a core competence to deal with, during end-of-life accompaniment. Even if guidelines on "good death" are available, nurses should continuously reflect on their experience, as Cipolletta \& Oprandi suggested $[26,49]$. Death and the process of dying always involve personal values 
and wishes, personal and social taboos, so that professionals facing this awkward existential phase need to discuss and reflect on their personal and professional experiences [31]. In so doing, they could perceive themselves as more effective in taking care of dying patients. Continuous training focused on reflective practice has been advocated for PC professionals, in order to improve their capability to face the effort of accompanying to death, and offering an always better care to patients and families [18,26].

We are aware that our findings cannot be generalized, since derived from a qualitative study conducted in a single site, with a small sample of nurses. Nevertheless, "our intent was not to develop something that was quantitatively representative, but to develop the concept or the theory as completely as possible, to represent the phenomena [in our case, the process of developing nursing competence in PC]"[50]. To this aim, the researchers' interpretation of the participants' words shouldn't be considered a bias. Investigators' subjectivity is inevitably involved in interpretative processes, but trustiness can be assured by continuous comparison of the emerging categories and discussion among researchers, and by external audit, both processes that we carried on.

Our findings may be useful to plan training courses for PC nurses in contexts that are similar to the one described here. Training directors should plan courses oriented to teach PC nurses in the perspective of patients' global management, where every patient can be seen as multi-faceted and unique. Further, PC nurses should be trained to develop a representation of families as a system integrated with patients, which can be managed with the staff's support. Training should be aimed also at constructing a non-idealized idea of PC team: conflicts often characterize multi-professional groups, but well trained professionals should be able to think about conflicts also as a chance for learning and growing.

Our study stresses the importance that accompanying to death must not be conceived and carried on as a solitary enterprise. In fact, professionals need to learn that this effort must be planned, carried on and discussed by an irreplaceable teamwork. Another issue emerged from this study is that continuous training is necessary for PC nurses. Our finding, however, could be strengthened by further exploring PC nurses' representation of competence, so as to plan and organise a focused and adequate training in PC.

\section{Conclusions}

Our findings suggest that nurses have developed their own set of norms and expectations of what palliative care is, before applying to PC training. However, during and after training, these perceptions change. Nurses transform their representation of the patient from a fixed and uniformed one to a multi-faceted image of him/her; they also change their perception of the family that from an obstacle becomes a system integrated with patients, which can never be excluded by the caring process; furthermore, nurses proceed from an idealized representation of the team to its perception as a real working group, characterised both by synergies and conflicts; they also learn that accompanying to death is a feasible team work and not a solitary endeavour; finally, nurses shift their focus from just relational needs of the patient to caring in PC intended as global management of the patient.

\section{Acknowledgements}

We thank Prof. Paola Di Giulio who collaborated on the external audit and Prof. Bruno Andreoni and Rocco Di Taranto who collaborated on data gathering.

\section{Authors' contribution}

MBGP was responsible of data collection and analysis, and manuscript writing. AD and ST participated in data analysis and manuscript revision. LZ was responsible of study design, participated in data collection and analysis and in manuscript revision.

\section{References}

1. Worldwide Palliative Care Alliance \& World Health Organization. Global Atlas of Palliative Care at the End of Life. WPCA \& WHO; 2014.

2. Casale G, Calvieri A. Palliative Care in Italy: a historical perspective. Medic. 2014;22:21-26.

3. SICP.Il core curriculum dell'infermiere in Cure Palliative.2013.

4. EAPC.Guida per lo sviluppo della formazione infermieristica in Cure Palliative. 2008.

5. Radbruch L, Payne S, Bercovitch M et al. White Paper on standards and norms for hospice and palliative care in Europe: part 2. European Journal of Palliative Care. 2014;17:22-31.

6. Polanyi M.The Tacit Dimension.New York : Anchor Books; 1966.

7. Ronsen A, Hanssen I. Communication in palliative care: Philosophy, teaching approaches, and evaluation of an educational program for nurses. Nurse Education Today. 2009;29(7):791-795.

8. Höcker A, Krüll A, Koch U, Mehnert A. Exploring spiritual needs and their associated factors in an urban sample of early and advanced cancer patients. Eur J Cancer Care. 2014;23:786-794.

9. Pattison N, Wood J. Palliative care in cancer: the challenge for how professionals can best meet patients' and families' needs. Eur J Cancer Care 2016;25:531-533.

10. Morini S, De Marinis MG. Problems and Perspectives in teaching concerning the palliative care. Medic.2014;22(1):13-20.

11. Strandberg EL, Ovhed I, Borquist L, et al. The perceived meaning of a (w)holistic view among general practitioners and district nurses in Swedish primary care: A qualitative study. BMC Fam Pract. 2007;8.

12. Pype P, Peersman W, Wens J, Stes A, Van den Eynden B, Deveugele M. What, how and from whom do health care professionals learn during collaboration in palliative home care: a cross-sectional study in primary palliative care. BMC Health Serv Res. 2014;7(14):501-532.

13. Dobrina R, Tenze M, Palese A. An overview of hospice and palliative care nursing models and theories. Int J Palliat Nurs. 2014;20(2):75-81.

14. Ferrell B, Malloy P, Virani R. The end of life nursing education nursing consortium project. Ann Palliat Med. 2015;4(2):61-69.

15. Grossman S. Educating RNs regarding palliative care in long-term care generates positive outcomes for patients with end-stage chronic illness. Journal of Hospice \& Palliative Nursing. 2007;9(6):323-328.

16. Coyle N. Introduction to palliative nursing care. In: Ferrell B, Coyle $\mathrm{N}$, editors. Oxford Textbook of Palliative Nursing. 3rd edition. New 
York:Oxford University Press;2010;3-11.

17. Kelly K, Thrane S, Virani R, Malloy P, Ferrell B. Expanding palliative care nursing education in California: the ELNEC Geriatric project. Int J Palliat Nurs. 2011;17(4):188-194.

18. Lessard S, Leclerc BS, Mongeau S. Family Caregivers Perceptions of Palliative Care in Home and Unit: The Balance between Given and Received Support. Palliat Med Care. 2014;1(3):1-10. DOI:10.15226/2374$8362 / 1 / 3 / 00115$

19. Heals D. Development and implementation of a palliative care linknurse programme in care homes. Int J Palliat Nurs. 2008;14(12):604609.

20. Venturini G, Pulimeno AL, Colasanti D, Barberi S, Sferrazza S, De Marinis MG. Validazione linguistico-culturale della versione italiana del questionario sulle competenze infermieristiche del progetto Tuning Educational Structures in Europe. L'Infermiere. 2012;49:39-48.

21. Slatten K, Hatlevik O, Fagerström L. Validation of a new instrument for self-assessment of nurses' core competencies in palliative care. Nurs Res Pract. 2014.

22. Landmark BT, Wahl AK, Bohler A. Competence development in palliative care in Norway: A description and evaluation of a postgraduate education program in palliative care in Drammen. Palliative \& Supportive Care. 2004;2(2):157-162.

23. Prem V, Karvannan H, Kumar S, Karthikbabu S, Syed N, Sisodia V, et al. Study of Nurses' Knowledge about Palliative Care: A Quantitative Cross-sectional Survey. Indian J Palliat Care. 2012;18(2):122-127.

24. Iranmanesh S, Farideh Razban, Batool Tirgari, Ghazanfari Zahra. Nurses' knowledge about palliative care in Southeast Iran. Palliative \& Supportive Care. 2014;12(3):203-210.

25. Donnelly S, Dickson M. Relatives' matched with staff's experience of the moment of death in a tertiary referral hospital. QJM. 2013;106:731736.

26. Cipolletta S, Oprandi N. What is a Good Death? Health Care Professionals' Narrations on End-of-Life Care. Death Stud. 2014;38(1):20-27.

27. Tornøe K, Danbolt LJ Kvigne K, Sørlie V. A mobile hospice nurse teaching team's experience: training care workers in spiritual and existential care for the dying - a qualitative study. BMC Palliat Care. 2015;18:14-43.

28. Griffiths J, Ewing G, Wilson C, Connolly M, Grande G. Breaking bad news about transitions to dying: A qualitative exploration of the role of the District Nurse. Palliat Med. 2015;29(2):138-146.

29. Goldsmith J, Wittenberg-Lyles E. COMFORT: evaluating a new communication curriculum with nurse leaders. J Prof Nurs. 2013;29(6):388394.

30. Bergdahl E, Wikström BM, Andershed B. Esthetic abilities: a way to describe abilities of expert nurses in palliative home care. J Clin Nurs. 2007;16(4):752-760.

31. Kendall M. Key challenges and ways forward in researching the "good death": qualitative in-depth interview and FG study. BMJ. 2007;334:521.

32. Arnaert A, Wainwright M. Providing care and sharing expertise: Reflections of nurse-specialists in palliative home care. Palliat Support Care. 2008;7(3):357-364.

33. Dunckley M, Aspinal F, Addington-Hall JM, Hughes R, Higginson IJ. A research study to identify facilitators and barriers to outcome mea- sure implementation. Int J Palliat Nurs. 2005;11(5):218-225.

34. Shipman C, Burt J, Ream E, Beynon T, Richardson A, Addington-Hall J. Improving district nurses' confidence and knowledge in the principles and practice of palliative care. J Adv Nurs. 2008;63(5):494-505.

35. Radcliffe C, Hewison A. Use of a supportive care pathway for end-oflife care in an intensive care unit: a qualitative study. Int J Palliat Nurs. 2015;21(12):608-615.

36. Denzin NK, Lincoln YS. The SAGE Handbook of Qualitative Research. Thousand Oaks (CA):SAGE;2011.

37. Glaser BG, Strauss AL. The discovery of grounded theory: Strategies for qualitative research. New Brunswick, NJ: Aldine Transaction:1967.

38. Corbin J, Strauss A. Basics of qualitative research: Techniques and procedures for developing grounded theory.4th ed. London:SAGE;2015.

39. Richards L, Morse J. Read me first for a user's guide to qualitative methods. 3rd ed. Thousand Oaks (CA):SAGE;2013.

40. Benner, P. From novice to expert: Excellence and power in clinical nursing practice. Upper Saddle River, Nursing Journal: Prentice Hall; 2001.

41. Charmaz K. Constructing grounded theory. 2nd ed. London:SAGE; 2014.

42. Taylor B. et al. Exploring idealism in palliative nursing care through reflective practice and action research. Int J Palliat Nurs. 2002;8(7):324330.

43. Ennis RH. Critical Thinking. Upper Saddle River, NJ: Prentice Hall; 1996.

44. Gallo LC, Penedo FJ, Espinosa de losMonteros K, Arguelles W. Resiliency in the face of disadvantage: do Hispanic cultural characteristics protect health outcomes? J Pers. 2009;77(6):1707-1746.

45. Ray JD, Overman AS. Hard Facts About Soft Skills. Am J Nurs. 2014;114(2):64-68.

46. Selman L, Robinson V, Klass L, Khan S, George R, Shepherd K, et al. Improving confidence and competence of healthcare professionals in end-of-life care: an evaluation of the 'Transforming End of Life Care' course at an acute hospital trust. BMJ Support Palliat Care. 2015;1-6.

47. Ferrell B, Virani R, Paice J,Coyle N, Coyne P. Evaluation of palliative care nursing education seminars. Eur J Oncol Nurs. 2010;14(1):74-79.

48. Taylor B, et al. Getting it right under pressure: action research and reflection in palliative nursing. Int J Palliat Nurs. 2008;14(7):326-331.

49. NICE Guidance .Quality standard for end of life care. UK: NICE Guidance; 2015.

50. Morse JM. Quantitative influences on the presentation of qualitative articles. Qualitative Health Research. 2007;17(2): 147-148. 